Books, videos, cd-roms, dvds and any other relevant items submitted for a review in the BDJ should be addressed to:

Mike Grace, Editor, British Dental Journal, 64 Wimpole Street WIG 8YS
Master Dentistry

Volume 2 - Restorative Dentistry, Paediatric Dentistry and Orthodontics

\author{
P. Heasman (Ed) \\ London: Churchill Livingstone, 2003 \\ price $€ 21.99$, pp378 \\ ISBN 0443061939
}

Nine contributors have written this text and although some topics, for example patient examination, aetiology of caries and toothwear, are visited in more than one chapter the editor has managed to avoid repetition well. Its ambition is to provide the student with all that they must know, most that they should know and some that they might know - quite a challenge! An interesting introductory section gives advice on how best to use the text and the section on examination technique is a sensible addition.

Chapters have a standard format, a brief outline of topics covered with learning objectives for each, and techniques highlighted through the use of boxes. Each chapter ends with selfassessment questions of varying format with complete answers given.

The restorative chapters cover periodontology, endodontics, conservative dentistry and prosthodontics. The first two provide good detail of their chosen area and include everything that you would expect. It is nice to see both child and adult patients discussed when considering gingivitis and periodontal disease. The endodontic section moves from patient assessment to canal obturation and also includes re-root treatment and surgical endodontics. Coverage of conservative dentistry in 25 pages is difficult especially when material usage is also discussed. Intracoronal restorative options are considered only briefly with priority given to adhesive techniques and extracoronal restorations. The prosthetics chapter sensibly confines itself to the clinical stages of complete and partial dentures, referring the reader to other texts for material science and laboratory stages.

The chapter on conscious sedation sensibly limits itself to techniques for "suitably trained" dentists in general community or hospital practice. Indications and contraindications to techniques are covered well and guidance on individual techniques is given. However, no specific advice is given on use of conscious sedation in childhood.

Paediatric dentistry is in two chapters that discuss behaviour management, prevention, restorative care for children, trauma as well as anomalies and medical problems. Orthodontics has three chapters covering development, assessment and treatment planning; management of occlusal problems and appliances and tooth movement.

The final chapter on law and ethics covers role and remit of the GDC and professional obligations. There is a useful section on complaints and a brief overview of employment law.

If I have a criticism it is on the over reliance of line diagrams rather than clinical photographs, but overall this is a nice text which it fulfils its objectives well.

\section{B. Chadwick}

\section{Clinical Manual of Implant Dentistry}

M. Davenport and H. Martinez

Surrey: Quintessence, 2002

price £55, pp271

ISBN 1850970491

The aim of this textbook is to provide practitioners and students with the scientific and clinical information necessary to understand implant dentistry. In this, the authors have succeeded admirably, although I feel the book will be of most benefit to those who are new to implant dentistry, rather than the more experienced implantologist.

The opening chapter deals with treatment planning. This is followed by three chapters which cover implant diameters, stage one and stage two surgery, peri-implant soft tissue management, impression taking, and screw retained verses cemented prostheses. The next four chapters deal with treatment considerations for edentulous people, partial edentulism, single missing teeth and implant treatment in the posterior regions of the mouth. Chapter nine highlights specific surgical procedures such as immediate implant placement, sinus grafting, guided bone regeneration and bone grafts. The final four chapters are on non submerged implant techniques, implants in young people, surface properties of implants and loading concepts.

At just over two hundred pages, the book can only give an overview of the many aspects of implantology. However, it is well written, clearly laid out and each chapter is followed by an appropriate list of references. The book is profusely illustrated with excellent photographs and diagrams. There are also numerous tables and lists which clearly spell out the indications and contraindications for the various techniques and procedures under discussion. Without a doubt, this book provides a very good introduction to implant dentistry.

\section{Davis}

\section{Introducing Dental Implants}

\author{
J. A. Hobkirk, R. M. Watson and L. J. J. Searson. \\ London: Churchill Livingstone, 2003 \\ price $€ 34.99$, pp 165 \\ ISBN 0443071853
}

This is a book with a strong pedigree and is based on the previously successful book also written by the authors "A Colour Atlas and Text of Dental and 

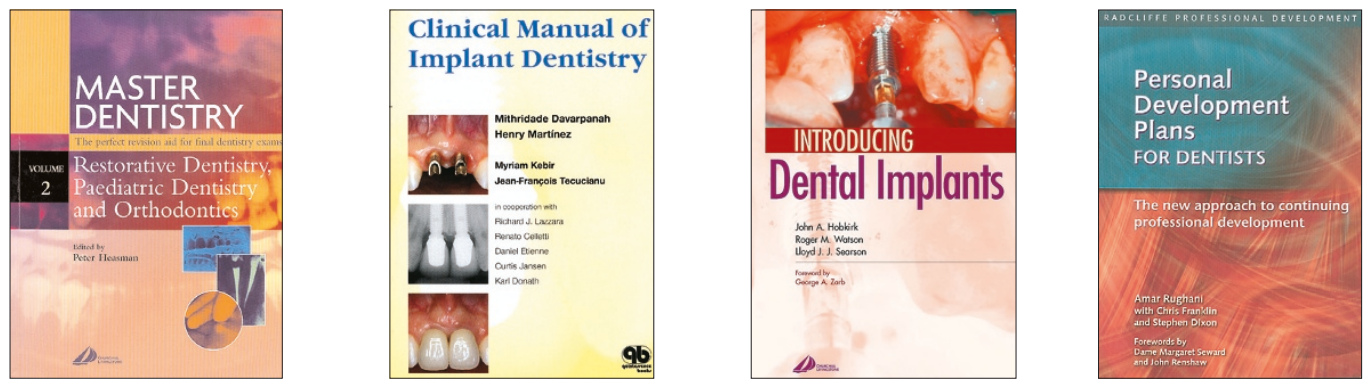

Maxillo-Facial Implantology”. The introduction by the authors states quite clearly that this is seen as an introductory book for undergraduate students in their final year, dentists taking postgraduate courses and professions complementary to dentistry. This is how the authors wish the book to be read and judged and this reviewer will evaluate it with these objectives in mind.

First impressions reveal a high quality production. The publishers have made a soft backed book which is light and easy to flick through. The pictures are great and each one beautifully reproduced. My first impressions were very favourable and I looked forward to reading the book. The book covers general treatment decisions, treatment planning, implant surgery, the edentulous and partially dentate patient, single tooth implants, other applications and problems. At the end of the book there are some self assessment questions which encourage the reader to revisit the material.

Although there is an abundance of good pictures, the text is disrupted with too many headings and this may discourage the casual reader from using the book. Many of the headings were rhetorical in nature and this style was somewhat difficult to follow. There were many answers to the questions raised and it is my opinion that novices require more guidance otherwise they will become lost in the overflow of material.

The information in this book can not be faulted and the pictures are of very good quality. There is a great deal of worthwhile material but the audience it is aimed at may well find that it is too detailed. It is an attractive book which will sell but I see it more as an overview of dental implants aimed at the more experienced user. Therefore the authors have partially succeeded in their aims by appealing to the dentist taking postgraduate courses. It will find a place as a reference book but will have difficulty in establishing itself as an undergraduate textbook and the material is pitched beyond the professionals complementary to dentistry. The market place for books covering dental implants is crowded and it can be argued that there are several other books that provide an easier guide to the subject.

D. Walmsley

\section{Personal Development Plans for Dentists. The new approach to continuing professional development.}

\author{
A. Rughani, C. Franklin and S. Dixon \\ Oxford: Radcliffe, 2003 \\ price $€ 29.95$, pp240. \\ ISBN 1857759176
}

This is book aimed at dentists but would also be suitable for the dental team, especially in view of revalidation and quality assurance. The emphasis is placed on encouraging dentists to become life long learners. The dental team learns from experience, feedback from peers, colleagues, or patients and this book shows how to harness these experiences to everyone's benefit.

The format is clear and easy to follow with good examples. Each chapter has an outline, key points, summary and a personal development plan form is included which in chapters 3-5 is fully illustrated with worked examples.

The authors in nine chapters outline the need for continuing professional development and how to develop, make and evaluate personal development plans (PDP). Making a PDP is a simple concept but requires time and commitment, and should not be too ambitious. In evaluating a PDP it is recommended that a balance be reached between learning needs / learner / trainer / patients / community / administration / practice / management and prioritisation of needs. PDPs are for an individual and limited to one year. Examples are provided including determining objectives which are specific, measurable, achievable, relevant, time- bound (SMART) and how to evaluate, amend and learn from outcomes. In the remaining chapters, use of additional tools to facilitate the process such PUNS (patient unmet needs); DENS (dentist's educational needs), significant event analysis (SEA), clinical audit and appraisal are described. Using PUNS and DENS provide the means for the dentist to prioritise and can offer a practice snap shot develop self-awareness and promotes regular reflection and team educational needs. Each SEA provides a means to harness good practice and to make improvements where necessary.

The authors outline a PDP format that is simple and practical. Clinical audit is described which could be used in a learning environment, identifying needs, and through learning and encouraging change to enhance good clinical practice and standards. Finally the authors consider appraisal, in that it is a means to recognise achievement, provide feedback and encourage further development. They point out that appraisal is not performance review. In conducting appraisal, a PDP is an important element to help identify achievements and need during the year and plans for improvement.

The book closes with a series of appendices which provide proformas for appraisal and meeting structure, dentist's self-evaluation, self-evaluation questionnaires (SEQs) including identifying learning needs: management and administration, and a GDP $360^{\circ}$ feedback form. All of these are essential in achieving a suitable PDP, which is achievable during the course of the following year.

I would have no hesitation in recommending this book, especially for those practitioners who are still unfamiliar with the tasks that are expected in the current climate. In general, using such tools in career development and satisfaction can be seen to provide a means to register / log, reflect, prioritise, plan and evaluate the learning cycle, which prevails.

E. Davenport 